\title{
Contador de Argote: um dialetólogo/sociolinguista avant la lettre?
}

\author{
Odete Pereira da Silva MENON*
}

\begin{abstract}
* Doutorado (1994) em Linguistique Théorique et Formelle - Université de Paris VII - Université Denis Diderot. Mestrado (1984) em Letras pela Pontifícia Universidade Católica do Paraná. Bolsista PQ2/CNPq. Professor voluntário no DALIC/UTFPR. Contato: odete@ufpr.br.
\end{abstract}

\section{Resumo:}

Embora nossos primeiros gramáticos tenham reconhecido a existência de diferentes modos de falar a língua portuguesa, parece ser Contador d'Argote o primeiro a empregar as palavras dialeto e gíria (para variedades do português) numa obra gramatical. Isso ocorreu na segunda impressão das suas Regras da Lingua Portugueza, à qual acrescentou informações em alguns dos capítulos da primeira impressão, necessárias "para a intelligencia dos Jdiotinmos da Lingua Portugueza", e a quarta parte "para o ennino mais polido, e para a gente nobre". Essa parte consta de um diálogo, entre $\mathbf{M}$ (estre) e $\mathbf{D}$ (iscípulo), que se inicia com: "M. Que quer dizer Dialecto?". Depois, passa a identificar as principais “cantas de dialectos": Dialectos locaes, de tempo e de profinnão. Mais que nomear, ele vai assinalando as diferenças que há entre eles, caracterizando-os, para finalizar a exposição falando do Dialecto runtico e dos Dialectos Ultramarinos. Nestes últimos (da India, Branil, \&r), ressalta, há "muytos termos das linguas barbaras, e muytos vocabulos do Portuguez antigo". E, fechando a "lição sociolinguística", fala de bum genero de Dialecto, a que chamão Giria que, em Lisboa, os homens "a que chamão de ganhar ... unão algumas vezes entre ni” e também de uma outra Giria, a dos "niganos" ...

\section{Palavras-chave:}

Contador de Argote. Dialetos. Gíria.

Signum: Estudos da Linguagem, Londrina, v. 22, n. 2, p. 167-191, ago. 2019

Recebido em: 28/08/2019

Aceito em: 12/02/2020 


\section{Contador de Argote: um dialetólogo/sociolinguista avant la le ttre?}

Odete Pereira da Silva Menon

\section{INTRODUÇÃO}

A apresentação de Contador de Argote, ${ }^{2}$ que não costuma ser citado em trabalhos de dialetologia ou sociolinguística do português, se justifica pelo fato de ele discorrer de maneira muito clara sobre conceitos - dialeto e gíria - que só vão se tornar moeda corrente em nossos cursos de Letras na segunda metade do século XX. ${ }^{3}$ Além de ser um ilustre desconhecido na nossa área, não foi sequer dos gramáticos mais prestigiados em sua época. A causa disso? Podemos aventar algumas hipóteses: (i) falta de mecenas para apadrinhar edições posteriores; (ii) falta de compreensão dos pares, que estavam mais interessados em regras ortográficas e em valorizar uma norma para o ensino; e (iii) para isso, o surgimento de gramáticas mais centradas na expressão correta da língua, que tiveram mais aceitação (basta verificar a sorte de alguns compêndios, como acontece

1 A primeira versão deste trabalho foi apresentada, sob a forma de comunicação, no $V$ CIDS Congresso Internacional de Dialetologia e Sociolinguística, na UFBA, em Salvador (MENON, 2018).

${ }^{2}$ Depois da apresentação da comunicação, encontrei na internet o trabalho de Leite (2011). Mais recentemente, consultei Kemmler (2013, onde constam detalhes da primeira impressão, de 1721) e Marques (2017), entre outros. São estudos na área da história das ideias linguísticas (historiografia da linguística).

3 Agradeço ao parecerista que me assinalou duas referências não citadas por mim. Como na presente situação de quarentena pela Covid-19 não me é possível consultar a História da Lingua Portuguesa de Serafim da Silva Neto (que, acredito, seja a referência indicada) na biblioteca da Universidade, transcrevo o texto do parecerista, para ficarem registradas tais referências:

"Apesar de concordar com a afirmação 'Contador de Argote não costuma ser citado em trabalhos de dialetologia ou sociolinguística do português', além das referências citadas na pág. 1, senti falta de:

a) SILVA NETO, S (1979, p. 561-564). A 1ª. ed. é de 1957. Nesse trecho, Silva Neto cita as 'Regras' de Jerônimo Contador de Argote, comenta-as e considera que aí se apresenta 'um razoável panorama da língua portuguesa' (SILVA NETO, p. 561).

b) CARDOSO, S. Sociedade pluridialetal. Variação e ensino da língua materna. IN: MENDES, Edleise; CASTRO, Maria L. S. (Org.). Saberes em português: ensino e formação docente. Campinas: Pontes Editores, 2008, p. 11-25. Nesse texto, Cardoso retoma uma palestra anterior, de 1995, publicada nos Anais do I Seminário de Lingüística e Língua Portuguesa. Goiânia: Universidade Federal de Goiás, 1995."

Ressalto que desconhecia a obra mencionada em b), que vou procurar adquirir e aproveitar em outra ocasião. 
algumas décadas depois, com o de Lobato ${ }^{2}$ com dezenas de edições e de adições sucessivas).

Embora desde os primeiros gramáticos portugueses se tenha feito menção à existência de diferentes modos de falar a língua, assim como os falantes contemporâneos dos autores sabiam reconhecer, linguisticamente falando, quem vinha de onde, parece ser, salvo engano, que Contador de Argote foi o primeiro a empregar as palavras dialeto e gíria numa obra gramatical, para designar variedades da língua portuguesa. E isso ocorreu na segunda impressão (1725) das suas Regras da lingua portugueza, à qual acrescentou informações em alguns dos capítulos das três primeiras partes da primeira impressão ${ }^{3}$ necessárias "para a intelligencia dos Jdiotifmos da Lingua Portugueza, e a quarta parte "para o emfino mais polido, e para a gente nobre".

Vejamos como, meio século antes de Argote, um autor seiscentista, João Franco Barreto (*1600-†1674), na sua Ortografia da lingua portugueza, discorre sobre diferenças dialetais (sem chamá-las assim, evidentemente) do português falado da sua época:

He efta letra a. fatal para os de entre Douro, \& //72// Minho, \& Beyrões, figuindofelhe outro a. porque nã os pódem pronunciar ambos ũ detras do outro, గẽ lhes meter de permeyo ũ y, \& affy havendo de dizer, a agua, a alma, infalivelmente hã de dizer ay agua, ay alma. Màs o mefmo vicio tẽ [fegundo Frey Regnialdo Acceto, ẽ o tefouro de fua língua] algumas terras de Italia, como as do Brexiano, \& Ariano do Rĩ, que por dizerem aqua, pane, cazo, barca, dizem, ayqua, payne, cayfo, bayrca, \&c (BARRETO, 1671, p. 72-73, negrito nosso).

Barreto faz uma observação bastante judiciosa quando analisa a relação entre pronúncia e escrita, quando trata da vogal /e/, descrevendo-lhe a articulação:

Do E. E Segunda vogal he letra fimplez, \& a mays vifinha, \& femelhante na pronunciação ao a, que nenhuma das outras vogaes; porque havendole de pronunciar e, \& continuandofe a voz, fe algũ tanto abrimos mays a boca, o feu fõ fe converte ẽ a. E afsi tẽ melhor fõ que as outras vogaes, excepto o o, porque nã le formata tã prontamente feu efpirito dos beyços, como o fõ do a.

Cuydam algũs que he de duas maneyras, porque afsi como dicemos do a, o pronunciamos ora longo, ora breve; como nefta palavra befta; que tomandole polo animal, tẽ o e breve; \& tomandofe pola arma tẽ o e, longo, \& fe efcreverá cõ acento agudo ẽci- $/ / 75 / /$ ma. ${ }^{[4]}$ Porẽ na pronunciaçã defta letra nã difcrepamos dos

\footnotetext{
${ }^{2}$ Veja-se o estudo de Assunção (2000), a respeito da gramática desse autor, que não cessou de ser renovada e ampliada, até muito depois da sua morte.

3 A primeira edição, de 1721, foi publicada sob o pseudônimo Caetano Maldonado da Gama.

${ }^{4}$ A grafia etimológica de besta, arma de atirar setas ou pelouros, era beesta, < balesta, (com síncope do [1] intervocálico e assimilação regressiva perfeita do [e] sobre o [a]), assim como também se escrevia geeral, < general. Depois houve a crase dos -ee-, resultando em vogal aberta (ou longa, como diz Barreto) que, durante algum tempo, foi assinalada por acento agudo: bésta.
} 
Latinos, fegundo o ufo de agora, porque do antigo nã podemos fazer refoluto juifo, nã fendo certos de como pronunciavam os efcritos, os mefmos falladores delles (BARRETO, 1671, p. 74-75, negrito nosso).

A sua reflexão sobre como - e se se pode fazer isso - eram pronunciadas as palavras por falantes de outras épocas é perfeitamente atual, quando trabalhamos com fontes escritas (anteriores à criação do gravador) e temos que (ou queremos) decidir sobre se o que está escrito reflete, de alguma forma, o que seria produzido no oral pelos falantes daquela variedade de língua.

Barreto também faz referência a certos hábitos linguísticos do "vulgo circunvifinho" de Lisboa:

õe

15. He da natureza do ditongo ãe: nelle devem de acabar todos os pluraes dos nomes, que nós acabamos ẽ ã, \& os Caltelhanos ẽ on, porque eftas duas línguas, como originadas da Latina, faõ analogicas; \& affi de coraçã, cordã, opiniã, roupã, quinhã, fermã, //105// que elles dizem coraçon, cordon, opinion, ropon, quinhon, fermon, diremos corações, cordões, opiniões, roupoẽs, quinhões, fermões: \& affi diremos calções, toltões, porquanto elles dizem calçones, toltones, \& nã calçães, toftães, como o vulgo circunvifinho de Lisboa coftuma, \& o que ãode acabar ẽ aẽs, acabam ẽ oẽs, como Capitoẽs, Alemoẽs, ẽ vez de Capitaẽs, Alemaẽs,\& femelhantes (BARRETO, 1671, p. 104-105, negrito nosso).

Note-se que o nós deve se referir aos portugueses, os de Lisboa, especialmente. Estes formam em -ões o plural das palavras terminadas em -ão, por analogia ao que acontece em espanhol, na qual o plural de -on ( $=$ ao -ão português que, na época, poderia ter a pronúncia -ã, como o grafa Barreto) é -ones. E o povo -vulgo-que não é de Lisboa tinha o hábito de produzir o plural -ães. Inversamente, quando deveriam produzir -ães, dizem -ões, como em capitães, alemões ...

Barreto volta a fazer referência aos habitantes da região de Entre Douro e Minho, quando trata das trocas entre $\mathbf{b}$ e $\mathbf{v}$, dizendo que o $\mathbf{b}$ "Tẽ muyta afinidade cõ o $\mathrm{v}$ confoante, a que os noflos ortografos modernos chama ve":

E affi muytos Portuguezes de entre Douro \& Minho,nã advertindo o que vay de uma a outra, as trocam ẽ a pronunciaçã; efpecialmente os que ficam mays chegados a Galiza, de tal maneyra, que a vento chamam bento, $\&$ em lugar de Bento dizem vento; por vos,volfo; bos,bollo: por vida, bida; \& quali todos os nomes, ẽ que há v, confoante, mudam o v ẽ b. \& como fe o fizeflem, por o fazer ás aveflas, o que nós pronunciamos per $\mathrm{b}$, pronunciam eles per $\mathrm{v}$ de forte que tambẽ as letras,como nas partes da oraçã, \& Ceus atributos ha Enaloge (sic) (BARRETO, 1671, p. 114, negrito nosso). 
Novamente vemos um juízo de valor atribuído a esse nós ( $=$ os que falamos corretamente), em detrimento da pronúncia dos de outra região, a qual deveria ser um marcador bastante acentuado, para muitos autores fazerem dela menção, ainda mais com o acréscimo do detalhe geográfico disfarçando a discriminação: "mays chegados a Galiza". Ora, os galegos eram motivo de chacota já nas peças de Gil Vicente, seja por exercerem as profissões mais baixas em Lisboa (a de carregadores de água e de outras coisas menos nobres, p. ex.), seja pela sua pronúncia, que os denunciava imediatamente aos interlocutores.

Assim, embora tenha feito observações sobre fatos de pronúncia de variedades regionais e sociais, meia década antes de Argote, em momento algum Barreto emprega o termo dialeto, para fazer referência a variedades do português. No entanto, veja-se o que ele diz, numa reflexão sobre a prescrição do uso de letras dobradas em português por outros ortógrafos:

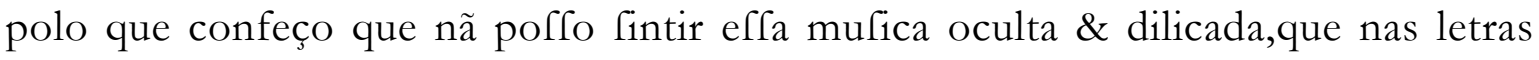
confideram alguns Ortografos noflos; finto fomente o do tambor,\& da trõbeta, como elles dizem, nã o inftrumento de cordas: porque ainda que alguns vocabulos, que dos Gregos ou Latinos tomamos, dobram acerca delles algumas confoantes, como noflas orelhas nã compreendem a diferença, que vay das fingellas ás dobradas, nã famos [sic] obrigados a confervar a analogia de $\int(e s$ taes vocabulos, que cada idioma tẽ fua ortografia \& dialetos proprios (BARRETO, 1671, p. 183, negrito nosso).

Parece, então, que a denominação de dialeto para variedades de uma língua não é desconhecida de Barreto; no entanto ele só vai usar tal palavra como referência mais geral: "que [=pois] cada idioma tem sua ortografia e dialetos próprios". Isso poderia, sem dúvida, incluir aí o português, mas não existe essa especificação, da parte dele, com relação ao idioma pátrio.

\section{Algum (Re)Conhecimento da Obra de Argote}

A falta de difusão da obra de Contador de Argote pode ter representado um atraso nas concepções de variação e mudança tanto em Portugal como no Brasil: tivemos que esperar que um francês "fundasse" a geografia linguística no século XIX para que o conceito de dialeto para fazer referência à variação espacial (estendida depois à temporal, à social e à estilística) entrasse nas preocupações acadêmicas de ambos os lados do Atlântico. ${ }^{5}$

5 Lembrar que, em 1920, Amadeu Amaral - que não era nem filólogo, nem linguista, mas jornalista - publicou o seu O Dialecto Caipira, obra pioneira na abordagem de uma variedade regional e social do português do Brasil. Na sua esteira, em 1922, apareceu O Linguajar Carioca, de Antenor Nascentes que, embora linguista, não ousou chamar de dialeto ao carioca. 
Prova disso é a menção feita a Contador de Argote por Leite de Vasconcellos nos seus Estudos de filologia mirandesa (1900) e, depois, na sua tese de doutorado Esquisse d'une dialectologie portugaise, apresentada à Universidade de Paris em 1901 (com segunda edição, organizada postumamente, em 1970, por Adelaide Valle Cintra, com base no exemplar pessoal do autor e incorporando as notas por ele deixadas).

Nos Estudos, Leite de Vasconcellos (1900, p. 26) faz referência a Contador de Argote, citando-o, a respeito do mirandês:

$\mathrm{M}-\mathrm{E}$ há mais dialectos locais?

D - Ha alguns lugares de Tras os Montes, e Minho, nas rayas de Portugal, que são muito bárbaros, e quase que se não podem chamar português, mas só os usa a gente rustica d'aquelles lugares'.

Parece que Contador de Argote teria noticia do mirandês, e acaso dos outros idiomas raianos, como o riodonorês e o guadramilês, mas nem os nomes chega a mencionar.[6]

Veja-se que, embora fale de Contador de Argote, que usa a palavra dialecto, Leite de Vasconcellos evita empregar essa denominação, qualificando imediatamente o falar de que se ocupa de mirandês e fazendo referência a outras variedades faladas nas raias como idiomas (riodonorês e guadramilês). Porém, ao seu primeiro trabalho sobre o mirandês, em 1882, havia dado o título de Dialecto mirandês, publicado no Porto, com suas primeiras observações, obtidas em trabalho de campo. $\mathrm{E}$ em muitos outros trabalhos (dele e de outros que se ocuparam do assunto) aparece uma indecisão em qualificar o mirandês como dialeto do português ou como língua autônoma (ou "idiomas", como na citação anterior).

$\mathrm{Na}$ Esquisse, Leite de Vasconcellos (1970, p. 3, folha de rosto interna), coloca em epígrafe um trecho de Contador de Argote:

to moda com que se falla = linmeg portuguesa nat lerras, $r$. 5. di Deita é diverno do com que se fall a mesmi em Lisbos, porque ent uma purte se usa de tumas palavras e pronuncis, e etr outra parte at las de outras,

D. JERONYMO CONTADOR D'ARGOTE, - Dar didectes da lingou porruguera $(1725)$.
O modo com que se fala a lingoa portuguesa, v.g. da Beira é diverso do com que se fala a mesma em Lisboa, porque em uma parte se usa de umas palavras e pronuncia, e em outra parte se usa de outras".

D. JERONYMO CONTADOR D'ARGOTE -- Dos dialectos da lingoa portuguesa (1725).[7]

No entanto, quase três décadas mais tarde, ele vai dar a primazia da classificação dos dialetos portugueses a Contador de Argote:

\footnotetext{
${ }^{6}$ Neste trabalho, todas as abonações seguem rigorosamente a grafia dos originais consultados. Nesse caso, aparecem palavras grafadas diferentemente daquelas que aparecem nas Regras de Argote (que transcrevemos adiante); porém aqui foi respeitada a grafia apresentada por Leite de Vasconcellos.

${ }^{7}$ Veja-se a nota 4.
} 


\section{GIRIA PORTUGUESA \\ I -- Lembranças curiosas}

O artigo do S.or C. A. Landolt, publicado á pag. 54-55 da Revista do Minho, sugeriu-me as seguintes notas.

Com raro senso crítico, o P.e D. Jerónimo Contador de Argote, nas Regras da Lingua portuguesa (conheço só a 2. ${ }^{a}$ ed., que é de 1725, Lisboa: a 1.a ed. é de 1721) enumera, e até certo ponto caracteriza, pela primeira vez de modo tão extenso, creio eu, alguns dialectos portugueses $(1) ; 8$ ao lado dos dialectos pròpriamente ditos coloca a giria, e diz: 'Tambem em Lisboa, entre os homens a que chamão de ganhar, ha um gênero de dialecto a que chamão giria, de que os taes usão algumas vezes entre si. E assim também os Siganos tem outra espécie de giria, por que se entendem huns e outros' (2). Argote infelizmente não menciona vocábulo algum; encarregou-se porém dessa tarefa Fr. Luís do Monte Carmelo no seu precioso Compendio de orthografia, Lisboa 1767. Dêle transcrevo o que traz:

'Giria ou gira he linguagem de marotos ou brejeiros. Os mais conhecidos termos da gira ou giria são os seguintes: [...] baiuca he taberna. / baiuqueira he taberneira. [...] calmar he espancar ou dar pancadas. [...] dez bofas sam dez reis [...] ganchorra he mão [...] safar he sumir ou furtar (VASCONCELLOS, 1929, p. 585).

O termo gíria já devia, então, estar incorporado entre as notações linguísticas, com a variante gira, pois dele fez registro Bluteau (*1638-†1734), em seu dicionário da língua portuguesa, publicado em 1789. ${ }^{9}$ Veja-se a definição apresentada a gira e gíria:

\footnotetext{
${ }^{8} \mathrm{O}$ autor faz chamadas para notas de rodapé, onde informa algumas referências bibliográficas, que não se reproduz aqui. Os negritos da citação são do original. As barras inclinadas, introduzidas na citação, são usadas para indicar nova linha, pois as palavras listadas por Monte Carmelo (cinquenta, no total) e sua significação são dadas por Leite de Vasconcellos num rol, cada uma ocupando entrada distinta, como verbetes de um dicionário. No entanto, em consulta ao Vocabulário portuguez e latino..., constatei que as palavras atribuídas por Leite de Vasconcellos a Monte Carmelo são praticamente as mesmas que constam do Bluteau (1713, v. 13, p. 75).

${ }^{9}$ Rafael Bluteau escreveu o Vocabulario Portuguez, L Latino, editado em 12 volumes em 1712. Foi, depois, "reformado, e acrescentado por Antonio de Moraes Silva, natural do Rio de Janeiro" como se lê na capa da edição de 1789. Assim, embora (pela raridade da primeira obra) a referenciação de Bluteau seja, em geral, a dessa edição reformada em dois tomos, pode ter havido muitos acréscimos aos verbetes originais daquele dicionário, como diz o próprio Moraes e Silva, no prólogo:

"Acompanhei efte eftudo com os auxilios do Bluteau, que achei muitas vezes em falta de vocabulos, e frazes; e mui frequentemente fobejo em differtações defapropofitadas, e eftranhas do affumpto, que fazem avolumar tanto a fua obra.

Efte ultimo reparo me animou a efcolher para meu ufo tudo o que elle traz propriamente Portuguez, deixando fómente os termos da Mythologia, os da Hiftoria antiga, e da Geografia, á imitação dos melhores Diccionariftas das línguas vivas. [...] Do que recolhi das minhas leituras fui fuprindo as faltas, e diminuições que nelle achava; e quem tiver lido o Bluteau, e conferir com o feu efte meu trabalho, achará que não foi pouco o que ajuntei; e mais podéra accrefcentar, fe as minhas circumftancias me não levallem forçado a outras applicações mais fructuofas. Todavia não venderei ao público por grande o ferviço que lhe fiz, bafta que conheça que lhe poupei a defpeza de I0 volumes raros; que lhe dou o bom que nelles ha, muito melhorado, e por huma decima parte, ou pouco mais do feu cufto, com a commodidade de não andar revolvendo tantos tomos; e ifto he alguma coifa, em quanto não aparece outra melhor" (BLUTEAU, 1789, p. vii-viii).
} 
GIRA, 「 f. linguagem dos garotos , figanos, e ladróes pela qual elles fe entendem , ufando de termos inventados, ou dando novo fentido aos ufuaes. [...]

GIRIA f.f. v. gira. \Circumlocução affectada.

(BLUTEAU, 1789, p. 660).

Como é possível perceber, os dois termos envolviam juízos de valor negativo, atribuindo-se o seu emprego por grupos marcados socialmente: garotos, ${ }^{10}$ ciganos e ladrões. Também já se pode flagrar o conhecimento dos processos de formação das gírias: (i) invenção, pura e simples, de um novo termo ou (ii) atribuição de sentido diferenciado a termos já existentes na língua.

Leite de Vasconcelos reconhece o trabalho de Argote como pioneiro, não só por tratar dos "dialetos propriamente ditos" (isto é, no sentido espacial), mas por classificar a gíria como um dialeto; ora, para nós, hoje, a gíria é um dialeto social. No tempo de Argote, quem a empregava eram os trabalhadores - diríamos hoje avulsos, biscateiros dentro do seu grupo; além de haver outra gíria, a dos ciganos, com que também se entendiam entre si. Ambos os grupos eram não muito bem conceituados. Essa maneira de pensar é referida também por Leite de Vasconcelos quando (como pesquisador de campo que era), lamentando o fato de Argote não ter dado exemplos de palavras, vai mencionar Monte Carmelo, autor que não só apresentara a gíria ou gira como "linguagem de marotos e brejeiros", como lhe dera uma lista de exemplos.

\section{Os Dialectos, De ARgote}

$\mathrm{Na}$ apresentação da segunda impressão (não se denominava ainda edição) das suas Regras, Contador de Argote enumera as novidades nela introduzidas, que justificariam essa nova impressão:

\footnotetext{
${ }^{10}$ Embora faça referência a garotos, em Bluteau não aparece registrado esse verbete; na p. 653, em que deveria estar, se fosse consignado, nada consta. Será que garotos estaria por marotos? Conforme a definição que se lhe atribui no Diccionario: "MAROTO, 1. m. moço plebeo mal compolto, e defcortez. [...] \U「a-「e adj. v.g., andar á marota, i. e. ao modo dos marotos". A entrada anterior, referente ao feminino do substantivo, contém significado bem mais eloquente quanto ao sentido negativo atribuído ao termo: "MAROTA, . f. f. mulher vil, meretriz" (BLUTEAU, 1789, t. II, p. 60). Houaiss data garoto de 1813; posterior, portanto, ao dicionário de Bluteau, reformado por Moraes e Silva (v. nota anterior). Maroto tem como data de aparição 1665, no Houaiss (HOUAISS; VILLAR, p. 955 e p. 1250, respectivamente). Consultei, posteriormente, o Vocabulario, de Bluteau (1712-1728), e lá não existe o verbete garoto. Então, pode-se deduzir que foi introdução de Moraes Silva, uma vez que, no seu Dicionário de língua portuguesa (1813) aparece o verbete garoto, como mencionado por Romano e Seabra (2014).
} 
Ultimamente advirto que os Capitulos, que neโta[11] [egunda impreโ[aõ vaõ accrecentados, que faõ muyta parte do quinto, e todo o fexto da terceyra parte, moftrou a experiencia que eraõ precifos para a intelligencia dos Idiotifmos da lingua Portugueza, e a quarta parte para o enfino mais polido, e para a gente nobre; como também o tratadinho da Orthografia, que vay no fim[12] (ARGOTE, Introducam, última página).

É interessante notar a preocupação do autor em justificar a nova parte introduzida: "para um ensino mais polido, e para a gente nobre". Preocupação com a formação mais refinada, mais política, como se dizia então, para fazer referência a aspectos da polícia, isto é, dos bons costumes [== polidez] em sociedade? Veja-se que o público alvo era "a gente nobre". É bastante comum se encontrar referências, nessa época, a gramáticas destinadas para senhoras, para gentis-homens ou nobres: nem se cogite que elas trariam considerações ou abordagens diferenciadas, para público diferenciado. Tratava-se simplesmente de resumos gramaticais, espécies de vademecum, para tirar dúvidas. Bastante reduzidas, poderiam ser consequência do alto custo de impressão de uma obra maior; com poucas páginas, elas circulariam mais e venderiam mais, evidentemente.

Essa quarta parte inicia com o capítulo I, "Dos dialectos da língua portuguesa" (p. 291-292), com explanação sob forma de diálogo, entre $\mathbf{M}$ (estre) e $\mathbf{D}$ (iscípulo). ${ }^{13} \mathrm{O}$ primeiro bloco de perguntas-respostas (01) serve para definir o que é dialeto e identificar os dialetos da língua portuguesa ("Dizey exemplo"):

(01) MESTRE. Que quer dizer Dialecto?

D. Quer dizer modo de fallar.

M. Que coufa he Dialecto?

D. He o modo diverfo de fallar a merma língua.

M. Dizey exemplo.

D. O modo, com que fe falla a lingua Portugueza nas terras v.g. da Beyra, he diverfo do com que fe fala a mef- //292// ma lingua Portugueza em Lisboa porque em huma parte fe ufa de humas palavras, e pronuncia, e em outra parte fe ufa de outras palavras, e outra pronuncia, naõ em todas as palavras, mas em algumas. Efta diverfidade pois de fallar, que obferva a gente da melma língua, he que fe chama Dialecto.

${ }^{11} \mathrm{O}$ símbolo $\boldsymbol{\Gamma}$ corresponde ao chamado esse longo (que no texto impresso fica mais evidente quando aparece grafado em itálico: $\boldsymbol{\Gamma}$ ), usado inicialmente em manuscritos medievais, ainda aparece na imprensa do século XVIII. Ocorria somente nas posições de ataque de todas as sílabas e de coda das sílabas inicial e medial; nunca em coda de sílaba final: nesta, é sempre o esse -s- normal. Quando está em início absoluto de frase, é sempre S; não há símbolo especial, nesse caso.

$12 \mathrm{O}$ tratadinho, como ele denomina, ocupa da página 341 à 356.

13 Os blocos ou partes de diálogos do Capitulo I da quarta parte da obra de Argote serão apresentados no formato de exemplos numerados. 
Depois dessas perguntas iniciais, o mestre indaga a respeito dos tipos -- caftas -de dialectos, a que o discípulo responde haver muitas, das quais três são mais importantes: os dialectos locaes, os de tempo e os dialectos de profiffa

\section{DIALECTOS LocaES}

Na sequência, vem a pergunta sobre o que seja dialecto local, com solicitação de exemplo:

(02) D. Dialecto local he a diferença, com que fe fala a mefma lingua em diverfas terras da melma nação.

M. Dizey exemplo.

D. A diverfidade, com que fe fala a lingua portuguesa nas terras da Beyra, e da Eftremadura, he Dialecto local (p. 292).

Indagado sobre quantos são os dialectos locaes do português, o discípulo responde que são muitos, mas cinco principais, "o da Provincia da Eftrema- //293// dura, o da Provincia de Entre Douro, e Minho, o da Beyra, o do Algarve, e o de Tras os Montes".

Em resposta à pergunta sobre o que seja o dialeto da Extremadura, o discípulo diz serem "a pronuncia, palavras, e modo de falar a lingua Portugueza ufado nas terras da Provincia da Eftremadura". A mesma resposta é dada para caracterizar o dialeto de Entre Douro, e Minho, e "o melmo le deve de dizer competentemente dos demais".

O questionamento sobre as diferenças entre o dialeto de Entre Douro, e Minho, e o da Extremadura, o discípulo responde:

(03) Differe na pronuncia, porque a letra $V$, confoante pronunciaõ como $B$, ao $V$ inho dizem Binho; a letra $B$, pronunciaõ como $V$ confoante, ao Vento dizem Bento. As letras aõ pronunciaõ om, ao Naõ dizem Nom, ao Paõ Pom. Differe nas palavras, porque à Viraçaõ chamaõ Marè, à Alameda chamaõ Devefa. Differem no modo de fallar, porque fazem a al- //294// guns nomes mafculinos femininos, e aos femininos mafculinos, $O$ fim dizem Afim. A febre dizem $O$ febre, e também mudaõ em alguns Verbos as terminaçoens das pelГoas, Eu eftive dizem Eu efteve. Eu fiz dižem Eu fez:

As diferenças apontadas dizem respeito à troca de [b] por [v]; à pronúncia do ditongo -ão; ao uso de palavras diferentes para designar coisas; à divergência de gênero gramatical de algumas palavras. O que ele chama de mudança na terminação dos verbos tem mais a ver com fatos de pronúncia do que de morfologia, pois esteve e fez são formas arcaicas, mais próximas ao étimo latino: seriam reminiscências de formas antigas conservadas naqueles dialetos mas evolucionadas no de Lisboa. 
Em seguida vem a caracterização das diferenças entre o da Beira e o da Extremadura; em (04) são exemplos da alternância de pronúncia do ditongo: entre [ow] e [oj], com a observação de que na Extremadura essa pronúncia seria regular.

(04) Differe na pronuncia, porque ao ditongo Ou fempre pronunciaõ $O y$, a Owvir dizem Oyvir, a Couves dizem Coyves. Efta pronuncia fe reteve no Dialecto da Eftremadura em muytas palavras, porque ao Couro dizemos Coyro, ao Mouro Moyro, ao Touro Toyro, \&c.

Além de Argote mencionar a diferença em palavras para designar coisas, a descrição que apresenta em (05) é importante para a história da língua portuguesa, porque registra um fenômeno linguístico de que Leite de Vasconcellos vai se ocupar em vários estudos, pois nas suas pesquisas de campo encontrou tais formas em algumas regiões de Portugal, ainda no século XX: trata-se da epêntese de um [j] entre o artigo a e o início de palavras com a letra a, como em água > aíagua; alma > aialma. Ora, esse acréscimo nada mais é do que a aplicação de regra antiga da língua portuguesa: evitar o hiato, que teve uma preponderância na alteração posterior de palavras que perderam a consoante sonora intervocálica, na passagem do latim para o português: arena $>$ area $>$ areia; pleno > cheo > cheio.

(05) Differe outro fim o Dialecto da Beyra do da Eftremadura, porque às palavras, que começaõ por $A$, accrecentaõ muytas vezes a letra I, Agoa dizem Aiagoa. A alma dizem Aialma. Differem nas palavras, porque aos Canteyros de flores, ou hortaliça chamaõ Leyras, aos Vagados Oyras, aos Rapazes Cachopos, às Raparigas Cachopas (p. 294).

E as diferenças entre o do Tras os Montes e o da Extremadura "condizem muyto com as da Beyra, e Entre Douro, e Minho". Quanto aos dialetos do Algarve e da Extremadura, eles diferem

(06) na pronuncia, porque ao $E$, fechado pronunciaõ como $I$, affim como Pedaço dizem Pidaço, e ao $I$, pronunciaõ como E fechado, allim como Dižer pronunciaõ Dezer, e em outras coufas. Meu dizem Mey, Seis horas dizem Seis joras.

Mais um fenômeno de pronúncia relevante para a história da língua: a comprovação de que já era corrente o alçamento da vogal média átona [e] para [i]. E se ele diz que o inverso era verdadeiro, o exemplo não é bom, pois se trata de um arcaísmo: dezerer por dizer. Outro dado interessante é a alternância do ditongo [ew], de Meu, para [ej], Mey, assim como a constatação de uma palatalização na junção de palavras - Seis horas dizem Seis joras - ['sej"3วras], provavelmente pela presença da semivogal palatal no ditongo [ej], como acontece em palavras em que esse ditongo vai se desenvolver quando o e inicial é seguido de fricativa: eijaminar [ej3ami'nar] < examinar [ezami'nar], em textos do séc. XVI. 
Quando o Mestre indaga a respeito da não inclusão do dialeto da província do Alentejo entre os demais, o Discípulo justifica ser ele pouco diverso do da Extremadura: "ao Concertar chama Amanhar, aos Cafaes chama Montes, \&c. e dizem tem alguns defeytos da pronuncia do Algarve" (p. 295).

Nessa última caracterização vemos aparecer um juízo de valor, ao chamar "defeitos" alguns fatos de pronúncia de Alentejo, que também ocorreriam no dialeto do Algarve. Outra apreciação negativa diz respeito a alguns outros dialetos locais, "de alguns lugares de Tras os Montes, e Minho nas rayas de Portugal, que faõ muyto bárbaros, e quali que fe naõ pòdem chamar //296// Portuguez, mas fó os ufa a gente ruftica da quelles lugares". Pense-se no efeito a produzir no leitor, com o uso cumulativo dos adjetivos barbaros e ruftica!

\section{DIALECTOS DE TEMPO}

A parte seguinte dos diálogos vai versar sobre os dialetos de tempo, que seriam três: antiquíssimo, antigo e moderno (uma das primeiras definições de periodização da língua portuguesa).

O Antiquiffimo é definido como aquele que se usou até o tempo de Dom Dinis, o sexto rei de Portugal, ou seja, até 1325. O Antigo, o que se usou até quase a perda do rei Dom Sebastião (1580), e o Moderno "he o que actualmente fe ufa da perda de ElRey D. Sebaltiaõ para cà" (lembrar que ele faz referência ao tempo da publicação do seu livro, 1725).

Sobre as diferenças entre os dois primeiros períodos e o moderno, o discípulo afirma que eles diferem entre si "em muytas coufas, principalmente o antiquiflimo, o que fe vè nos livros, e doaçoens antiguas. Bafte faber que tinhaõ muyta parte do Dialecto actual do Minho, Beyra, e Tras os Montes". A consideração é invertida, no autor: era aquele dialecto actual (coevos do autor) das três regiões que tinha conservado características do dialecto antiquiffimo!

A seguir, vem uma indagação bastante interessante, sobre se é necessário "Cabellos"; ao que responde o discípulo: "Para as peffoas curiofas, e doutas he //297//

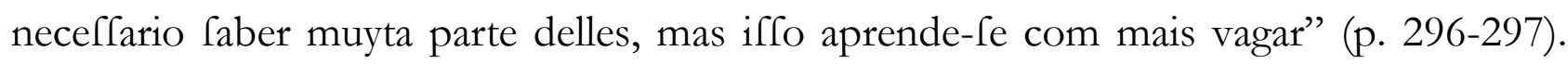
Isto é, ele considerava que conhecer os dialetos mais antigos não era objetivo do ensino aos meninos, a quem o seu livro era destinado; além disso, seria preciso muito tempo para aprender a conhecer esses dialetos.

\section{DiALECTOS DE PROFICĨO}

Dos dialetos espaciais e temporais, passa o diálogo a delimitar o que chamaríamos hoje de dialetos sociais. A primeira pergunta é sobre o que seja dialeto de 
profiffão: "He a differença de fallar a mefma lingua, de qu ufaõ os que exercitaõ diver「a profilfaõ de fallar". Veja-se que o autor concebe dialeto como variação, diríamos hoje, da mesma língua, num mesmo intervalo temporal - de $\overline{\mathbf{q}} \mathbf{u f a} \tilde{\mathbf{o}}$ (presente do Indicativo) pessoas que têm profissões diferentes. Na sequência, o discípulo vai tentar clarificar qual seja a diferença entre a divisão em dois, nessa categoria, verso e prosa:

(07) D. Quem fala, ou efcreve hum fucceffo em verfo, conta-o com muyta diferença, do que quẽ o conta em profa, e a efta differença chamo Dialecto de profif $\int a 0 ̃$ lem entrar na difputa fe efta divifaõ he própria, ou impropria. [...] Dous no fentido, em que aqui tomo a palavra Dialecto. [...] O da profa, a que chamaremos Profaico, e o do verfo, a que chamamos Poetico (p. 297).

É interessante observar como se dá a classificação de dialeto de profissão, para Argote: Poetico e Profaico. Ele não se refere a dialetos sociais como hoje concebidos, como a expressão de cada profissão: só aparece referência a duas profissões, daqueles que se dedicam à escrita: poetas e prosadores (embora ele empregue "fallar a melma língua" ou "profiৎfaõ de fallar", no sentido de "usar"). Toda a reflexão que se segue vai ser direcionada para as diferenças entre os dois estilos, como diríamos hoje.

É necessário lembrar que os textos de peças de teatro, desde Gil Vicente, eram primordialmente em verso. Embora houvesse peças em prosa, parece que o verso ajudava o autor, sobretudo o de comédias, o satírico ou dos entremeses, não só a passar a mensagem, como possibilitava jogos verbais impossíveis na prosa. No teatro também havia músicas entremeadas. Além disso, no teatro era possível inserir a fala das personagens, de uma maneira pelo menos muito próxima da sua fala real, além de outras liberdades verbais. Isso já tinha acontecido em séculos anteriores: basta atentarmos para a linguagem das cantigas de escárnio e maldizer dos primeiros cancioneiros, que muitas vezes ainda hoje choca alguns leitores pelo seu caráter realista (dizer as coisas com as palavras reais, não com eufemismos).

No entanto, Argote parece privilegiar o verso mais erudito, mais trabalhado, pois caracteriza o dialeto poético como "o modo de falar, que ufamos quando contamos algum fucceflo, ou o efcrevemos em verfo", que difere do Prosaico "nas palavras, e na ordem das palavras" conforme as respostas (08) e (09):

(08) Porque ao que o Dialecto Profaico chama Throno, o Poetico muytas vezes chama Solio, ao Sol chama Febo, ao Chegar diz Appropinquar. Ao Ceo chama Polo, \&c (p. 298).

À pergunta do mestre sobre o porquê difere na ordem de palavras, o discípulo responde: 
(09) Porque o Dialecto da profa fempre conferva a ordem natural das palavras, fegundo deyxamos dito na Syntaxe. Porèm o Dialecto Poetico muytas vezes naõ conferva a tal ordem, antes ufa da figura Hyperbaron, e Synchifis, que explicamos no Capitulo quarto da Syntaxe figurada (p. 298).

Quando dá o exemplo de diferença na ordem das palavras, em (10),

(10) D. O Sileno bufcava

Daquellas que a ferra deu bacantes

Já que Ninfas as nega Jer errantes

O hombro fem aljava (p. 299).

, explica o significado de algumas palavras: Sileno $=$ o Guarda; Bacantes $=$ Loucas; Ninfas $=$ Mulheres; Errantes = Vagabundas, dizendo que a ordem das palavras está toda confusa e ordenada no Dialecto familiar devia ser como em (11):

(11) Bufcava ao guarda daquelas mulheres loucas, que vinhaõ pela ferra, pois o naõ trazerem aljava no hombro moftrava nã̃ ferem mulheres vagabundas (p. 299).

$\mathrm{Na}$ diferenciação entre Poético e Prosaico, Argote caracteriza este último como sendo aquele que é usado quando se fala "familiarmente": parece ser uma denominação para designar o que hoje chamamos de língua comum. Na realidade, o contraponto está nos diferentes estilos de uso da língua, o que classificou como dialetos diferentes: um mais solene, mais trabalhado, que emprega as chamadas figuras de linguagem, o Poético, e outro, mais chão, que conserva a ordem natural das palavras, usado habitualmente nas situações normais, o Prosaico.

Depois de encerrado o primeiro capítulo, vem o segundo, Da Conftruiçaõ da língua Portugueza (p. 301-311), com finalidades nitidamente pedagógicas. Nele se expõe a prática da transformação do Dialecto Poetico em Profaico. A Conftruiçaõ consta de duas partes: "Trocar as palavras, e mudar-lhe a ordem" (p. 302):

D. Trocar as palavras he em lugar de humas palavras de huma lingua, ou Dialecto, pòr outras de outra lingua, ou Dialecto, que fignifiquem o melmo, como acima fica dito. Mudar a ordem das palavras he pòr na ordem natural as palavras, que na lingua Latina, ou no Dialecto Poetico eftaõ confufas pela figura Hyperbaton, como diffemos no Capitulo antecedente (p. 302).

Argote assinala que a ordem "confufa" é uma das características do Dialecto Poetico. Para restabelecer a ordem (e o bom entendimento) de um trecho de texto é necessário; ( $)$ utilizar os Vocabularios (=dicionários), para poder trocar as palavras de uma 
língua para outra ou as de um dialeto para as de outro dialeto; (iv) seguir as regras da Conftruição para mudar as palavras da ordem confusa para a ordem natural:

São as regras, que enfinaõ a pòr em huma lingua na ordem natural as fignificaçoens daquillo, que em outra lingua, ou Dialecto estava na ordem perturbada, e confufa. [...] Primeyra regra. Na Conftruiçaõ a primeyra palavra, que fe deve bufcar na Oraçaõ confufa, he o nome, que faz na Oraçaõ, e ferve ao Verbo de nominativo ou claro, ou occulto, e efta le deve pòr primeyro na Oraçaõ feyta na ordem natural, e Dialecto da profa (p. 303).

E na sequência dessa primeira seção do capítulo, aparecem exemplos aplicados a essas transformações de estilo, desfiando uma análise morfossintática, com as funções designadas com os nomes dos casos latinos (nominativo para sujeito; acusativo para objeto direto; dativo, para indireto etc.).

Na segunda seção do capítulo II, intitulada PRATICA da regencia da Grammatica Portugueza conforme a regencia da Latina, Argote insere um texto de Vieira (em prosa, naturalmente), e vai aplicar ali a análise morfossintática:

Para intelligencia clara do modo, com que fe deve enfinar efta Grammatica, e para que os meninos fe facilitem pela regencia della à regencia, e regras da lingua Latina, me pareceo propor aqui o exercicio pratico das regras, que temos dado, e delle ufáraõ os Meftres na fórma, que dizemos na Introducção, que vay no principio defta Grammatica.

Para idèa pois, e exemplar defte exercício, e regencia pratica, efcolhi huma Carta efcrita pelo infigne Padre Antonio //311// Vieyra da companhia de Jefus ao Eminentiffimo Cardial [sic] de Lancaftre, a qual naõ anda impreffa atèqui, e ma participou hum amigo, e he a feguinte (ARGOTE, 1725, p. 310-311, negrito nosso).

E dizendo que a Carta contém quatro períodos (o texto contém quatro pontos finais, antes da frase final Deos guarde a Voffa Eminencia. e da datação, Babia 14. de Julho de 1690.), começa a lição de análise morfossintática: "M. [...] Dizey que coufa he Eminentiffimo? / D. He nome adjectivo fuperlativo". Desce o nível de análise: "M. Porque he nome? / D. Porque tem números, e fe declina por calos". O processo analítico se aplica a quase todos os componentes da Carta.

\section{DiALECTO RUITICO}

Depois dessa elegante distinção entre dois estilos, vem a indagação sobre haver mais algum dialeto. O discípulo vai discorrer sobre o Dialecto ruftico: 
(12) Ha hum modo de fallar a lingua Portugueza mao, e viciado, ao qual podemos chamar Dialecto ruftico, e delle ufa a gente ignorante, ruftica, e incivil, e delle he neceflario defviar aos meninos bem criados (p. 299).

Em (12) presenciamos um ataque contra a fala das pessoas sem instrução, que ele qualifica como "ignorante, rústica e incivil", que fala "mao e viciado" e que, por isso, não pode nem deve ser apresentado aos "meninos bem criados": não é de bom tom.

O mestre, então, classificando-o de mao Dialecto, pergunta ao discípulo em que ele difere do Dialecto verdadeyro. O discípulo responde que as diferenças estão na pronúncia, nas palavras e no modo de falar a língua portuguesa. Solicitado a dar exemplos, o discípulo diz o conteúdo em (13):

(13) Para dizerem os rufticos Por certo, dizem Bofé. Aos Toftoens dizem Toftaens, aos Grãos Grães, \&c. A letra $Z$ muytas vezes pronunciaõ como $G$, ao Viæitar dizem Vigitar, à Vizita Vigita. Eu fizera dizem Eu figera, Eu trouxe dizem Eu trouve, a Ouvido dizem Ouvifto. Atreverfe dizem Ejtreverfe. Flores dizem Froles, \&c (p. 300).

O autor, na realidade, está caracterizando a linguagem dos rústicos como antiquada, pois os exemplos ali enumerados são quase todos sentidos como arcaicos pelos falantes do século XVIII. E, convenhamos, desse mao Dialecto, permanece na língua, ainda hoje, pelo menos uma das formas condenadas: a forma ouvisto (cruzamento de visto e ouvido) continua a fazer parte da língua portuguesa das pessoas menos (ou mais ou menos) instruídas. A maioria das diferenças no "modo de fallar a língua portugueza" diz respeito a diferentes pronúncias; há algumas lexicais: por certo / bofé e umas poucas morfológicas, como ouvisto e estrever-se.

\section{DIALECTOS ULTRAMARINOS}

Depois da fala dos rústicos, é a vez do português de ultramar:

(14) Ha os Dialectos ultramarinos, e conquiftas de Portugal, como India, Brafil, \&c. os quaes tem muytos termos das linguas barbaras, e muytos vocabulos do Portuguez antigo (p. 300).

A definição dos dialetos ultramarinos, sem muitas delongas, inclui a observação de que eles contêm termos das línguas bárbaras - o que quer que isso signifique porque muitas das línguas de onde provieram empréstimos ao português não eram de povos bárbaros, como os próprios portugueses reconheceram. Haja vista a admiração dos intrépidos missionários que se aventuraram a conquistar a China para a fé de Cristo, quando viram os templos, as ruas pavimentadas, a organização social e administrativa dos chins, em muito superior ao Portugal recém-saído da era medieval. 
Além disso, no século XVIII, era possível constatar, na metrópole, que a língua portuguesa transplantada para aqueles longínquos rincões havia conservado uma boa parcela de palavras antigas - mas o autor não percebe ou não deixa perceber se o sabia que indicavam valores e referências que haviam se conservado dos séculos XVI e XVII (período áureo das navegações e conquistas), mas que já não vigoravam no Portugal continental, como atesta a percepção do autor em (14), quando fala em "Portuguez antigo".

Em contraponto, as terras de ultramar com a sua nova realidade cultural e material exigiam palavras novas, existentes em tantas outras línguas: banana, chá, coco, anfião (ópio), benjoim, pedra bazar, ruibarbo, veniaga (comércio, negócio), teca (madeira leve), mandioca e a sua farinha de pau, abacaxi, jacaré, moleque... que acabaram por fazer parte da língua portuguesa, algumas delas até hoje.

\section{GIRIA}

E, finalmente, aparece um dialeto especial: a gíria, que recebe de Argote a seguinte descrição:

(15) Tambem em Lisboa entre os homens, a que chamaõ de ganhar, ha hum genero de Dialecto, a que chamaõ Giria, de que os taes ufaõ algumas vezes entre fi. E aflim tambem os Siganos tem outra efpecie de Giria, porque fe entendem huns com os outros (p. 300).

Em (15) podemos observar um recorte da sociedade portuguesa, pela menção aos "homens de ganhar" - correspondentes talvez aos atuais biscateiros e quebra-galhos - e aos ciganos: ambos caracterizam grupos marginais (no sentido de "à margem da sociedade") e, por isso, malvistos. Argote não deixa de assinalar que a gíria dos "homens de ganhar" é uma, e a dos ciganos é outra. E que essa linguagem especial é usada internamente pelos membros de cada grupo, pela qual eles se entendem entre si.

Os ciganos foram, desde há muito, marcados como um povo constituído de ladrões e enganadores, porque sempre ludibriavam os compradores das suas mercadorias e de animais (e as ciganas, também, com a sua leitura das mãos, para ver a sorte das pessoas) e, por muito tempo, como traficantes de crianças, pois quando uma criança desaparecia, imediatamente se culpava a tribo de ciganos que havia nas vizinhanças: acreditava-se que eles roubavam as crianças e as vendiam.

Os "homens de ganhar" também poderiam incluir aqueles que furtavam objetos e depois os vendiam na Feira da Ladra (ainda hoje ela funciona, às terças e aos sábados, em local vizinho da igreja de São Vicente de Fora, como feira de objetos usados, mas 
também de novos) que, no século XVI-XVII, localizava-se na Ribeira ou no Rossio, conforme atestam algumas peças de teatro. ${ }^{14}$

Camões (2007, p. 18), organizador de Teatro Português do Século XVI, diz, na caracterização do Auto dos Escrivães do Pelourinho: ${ }^{15}$ "É um auto de atualidade, que parece coincidir com a mudança de local da Feira da Ladra, como se depreende dos versos 5660 [...] ou, pelo menos, com um boato sobre a transferência de local". Em seguida, acrescenta um dado relevante, que é o fato de, já em 1552, João Brandão (de Buarcos), na sua Grandeza e Abastança de Lisboa em 1552, "descrever a enor-//19//me Feira (da Ladra) que se realiza já no Rossio, às terças-feiras ( $\mathbb{2} 21)$ : "Direi da Feira que se faz nesta cidade cada oito dias, no Rossio dela, que é certo grandeza da terra" (CAMÕES, 2007, p. 18-19).

Estes são os versos do Auto dos Escrivães do Pelourinho, sobre a transferência da Feira da Ladra para o Rossio:

GONÇALO Cousa é de grande avio

que a nós muito nos quadra

de que eu me maravilho

e que é a Feira da Ladra

que se muda ao Rossio

(Escrivães, v. 56-60, Camões, 2007, p. 107).

Mas no Auto há também uma indicação explícita de uma das atividades mais lucrativas da Feira da Ladra (receptação e venda de objetos furtados): é o longo diálogo (versos 181-240) entre o ESCRIVÃO PRIMEIRO ${ }^{16}$ e o ESCRIVÃO SEGUNDO, a respeito do moço do PRIMEIRO, que ainda não tinha chegado com a mesa no local onde o escrivão exercia o seu mister (ofício) de escrever cartas para quem solicitasse. Também o SEGUNDO se queixava de o seu moço ainda não ter chegado, a que responde o PRIMEIRO que talvez "foi vender a mesa para jogar". Mas, em seguida, o SEGUNDO vê o seu moço chegar. Então, o PRIMEIRO se lamenta:

\author{
ESCRIVÃO PRIMEIRO: A minha mesa é vendida \\ pois ela aqui não vem. \\ Nunca mais me hei de fiar \\ em moço que eu tiver //114//
}

\footnotetext{
${ }^{14}$ Inclusive foi título de um auto, de Baltasar Dias, o Auto da Feira da Ladra, 1619, conforme Camões (2007, p. 10).

15 Publicado pela primeira vez em 1625, por António Álvares, em Lisboa, conforme Camões (2007, p. 105).

${ }^{16}$ Nesse original (como em outros em que se usa essa maneira de escrever), as palavras escritas em maiúsculas - ESCRIVÃO PRIMEIRO, SEGUNDO ... - são representadas em tipo menor do que o do texto normal, o que aqui reproduzo, por fidelidade à fonte.
} 
sempre eu ouvi dizer

que é melhor só estar

que mal acompanhado viver.

Eu o vou logo buscar

per i por esta Ribeira

e hei-o bem de fustigar

(v. 224-233, p. 113-114, negrito nosso).

A que se segue o diálogo entre os dois, em que aparecem as duas possibilidades de o PRIMEIRO encontrar o seu moço: ou ainda vendendo a mesa na Feira, ou já a tendo vendido, ter ido jogar com o dinheiro obtido na venda:

\section{ESCRIVÃO SEGUNDO Havei-lo de achar na Feira \\ da Ladra ou a jogar.}

ESCRIVÃO PRIMEIRO Lá o quero ir buscar.

Se ele aqui vier ter

fazei vós polo tomar.

ESCRIVÃO SEGUNDO Se ele aqui vier

eu o farei aqui estar.

(v. 234-240, p. 114, negrito nosso).

Nesses diálogos, temos a informação de que a Feira da Ladra ainda se encontrava localizada na Ribeira, que complementa o boato da transferência para o Rossio, indicado por Gonçalo, nos versos 56-60, acima transcritos. Esse é um bom exemplo de como, às vezes, uma pequena indicação perdida numa peça ou num texto pode sinalizar a possibilidade de se datar alguns acontecimentos ou documentos.

Em termos de datação, o termo gíria parece ter estado em uso desde, pelo menos, o início do século XVIII, pois Bluteau (1713) já lhe atesta a existência, ao atribuir-lhe o foro de verbete de dicionário, ou melhor, verbetes, pois inclui também a forma gira:

GIRA. Segundo o P. Guadix, he nome Arabico,que val o melmo, que comida, com galhofa, \& abundancia; Entre nòs Gira he o melmo, que a Lingoagem dos marotos. Os termos mais fabidos da Gira faõ eftes.

Artife, quer dizer Paõ, /[17] Avezar, Eftar. / Baftos, os dedos. / Bola, a cabeça. / Bayuca, Taverna. / Bayuqueiro, Taverneiro. / Calcorrear, Correr. // coluna 2// Calcos, Sapatos. / Catropeo, Cavallo. / Cria, Carne de vaca. / Cachimbos, Os pés. / Casebre, Caßa. / Criar, Ter alguma coufa. Criar minas de caroço, Ter, ou Pofluir muito. / Cheta,

\footnotetext{
17 Usa-se, aqui, a barra inclinada para indicar término de linha, pois a relação, no dicionário, ocupa praticamente uma coluna inteira, cada entrada em uma linha. As duas barras indicam mudança de coluna: em outras situações, indica-se a mudança de página colocando-se o número da página seguinte também entre barras duplas inclinadas.
} 
Vintem. / Dez Bofas, Dez reis. / Encanhas, Meyas. / Falfo, O lenço. / Faxo, Pao. / Ganiços, Dados. / Giropa, Caldo. / Ganchorra, A maõ. / Gaio, Piolho. / Gris, Feio. / Golpe, Algibeira. / Gubio, Chapeo. / Jorna, Vagar. Eftou. / Jornando, Naõ quero fahir. / Jufta, Cafaca. / Lima, Camifa. / Marca. Puta. / Marco, que fe aveza. Homem, que eftá prefente. / Monteira, Carapuça. / Pilra, Cama. / Purrio, Bebado. / Pio, Vinho. / Rata, fome. / Rede, Capa. / Roda, Toltaõ. / Ruftir, comer. / Surrar, furtar. / Tardar, $\mathrm{O}$ veftido. / Tiba, faca. Tirantes, Calçoens. / Hum pobre Ganifaro, quer dizer, hũ pobre tonante, ou manganaõ. Vai com os arames. Vai com elpada, \& daga. Calma-lhe com o faxo na bola, quer dizer Dalhe com o pao na cabeça, \&c (BLUTEAU, 1713, v. IV, p. 75).

Depois vem o verbete GIRIA, em que o autor remete ao termo GIRA:

GIRIA. Vid. Gira. os que tomaõ GIRIA por huma jocola, ou affectada circũlocuçaõ, com que le diz em muitas palavras, o que ve podèra declarar em poucas, o derivaõ de Girar ou Giro, por Rodeo. Iocofa circumlocutio, ${ }^{18}$ ou circuitio, onis. Fem. Affectatus loquendi circuitus, us. Mafc (BLUTEAU, 1713, v. IV, p. 77).

\section{Dialecto, Conforme Bluteau}

Como Bluteau era contemporâneo de Argote, tendo ambos publicado suas obras nas duas primeiras décadas do século XVIII (de 1712 a 1728, para o primeiro, e 1721 e 1725 para o segundo), provavelmente compartilharam o mesmo estado de língua portuguesa. Assim, vemos que tanto um como outro empregaram a palavra diale(c)to que, então, deveria já estar em voga na esfera das discussões a respeito de língua. Como já era de domínio comum, sabia-se que a língua mudava com o tempo, pois muitos gramáticos falavam em fases da língua portuguesa. O que constituía novidade era a percepção de que ela apresentava diferenças no espaço físico, num mesmo intervalo temporal. E, como se divisa em Argote, também se reconhecia alguma divergência em relação à maneira de se comunicar conforme a profissão que se exercia. Além disso, alguns grupos sociais específicos usavam um tipo de língua especial cujo conhecimento e domínio era exclusivo deles.

Embora a obra de Bluteau tenha sido publicada paulatinamente, de 1712 a 1728, os dois primeiros volumes apareceram em 1712; o terceiro, que contém o verbete DIALECTO (p. 205), e o quarto, onde está GIRA (p. 75) e GIRIA (p. 77), em 1713; o quinto, que apresenta MARÓTO (p. 340), em 1716. MAROTO (e MAROTAGE) vai ser retomado no volume nove, Suplemento (p. 20), em 1727. Pode-se supor, então, que Argote teria conhecimento e acesso a essa obra, na qual teria podido se embasar ou se inspirar para reformar e acrescentar a obra que publicara em 1721.

18 O Vocabulario de Bluteau era portuguez. e latino ... 
Para que se possa avaliar quão próximas estão as definições, vou proceder à reprodução do verbete DIALECTO, tal qual ele aparece em Bluteau (embora seja uma longa citação, creio que vale a pena reproduzi-la para o leitor comparar ambos os autores):

DIALECTO. Modo de fallar proprio, \& particular de huma lingoa nas differentes partes do melmo Reino; o que cõfifte no accento, ou na pronunciaçaõ. ou em certas palavras, ou no modo de declinar, \& conjugar; \& affim vemos, q no mefmo Reino de Portugal os da Provincia da Beira, de Entredouro, \& Minho \&c. naõ fallaõ, nem pronunciaçaõ (sic) [19] o Portuguez do mefmo modo, que os filhos de Lisboa. Dialectus, $i$. Fem. Os noffos melhores Grammaticos naõ tẽ efcrupulo de tomar efta palavra do Grego. Quintiliano the chama, Loquendi genus. EIte orador fallando dos Gregos, no cap. 9. Do primeiro livro das fuas Inft. diz Plura illis loquendi genera, quae Dialectus vocant. O mefmo no capitulo feguinte chama o dialecto Eolico. AEolica ratio. Sive illa (nomina) Ex Graecis orta tractemus, quae funt plurima, praecipuèque AEolicâ ratione, cui eft fermo nofter fimillimus, declinata. O fom, \& a斤fento da pronunciaçaõ, a que chamaõ Dialecto, \& $\%$. Affim, fe falla a mefma lingoa Italiana em Napoles, \& Veneza, mas com diferente cõfonancia da Romana. Vieira. Xavier //206// accordado, p. 448 (BLUTEAU, 1713, v. III, p. 205-206).

Em se tratando de um dicionário, não se manifesta ali a dicotomia apresentada por Argote, nós x os outros, da Beira, de Entre Douro e Minho, da Extremadura, do Algarve: Bluteau emprega "os filhos de Lisboa", em contraponto com as outras regiões do Reino. Depois da parte da definição de dialeto no tocante ao português, o dicionarista insere a chamada em latim: Dialectus, i. Fem. (sic), pois seu Vocabulario abrange ambas as línguas. Mas, imediatamente, faz uma observação em relação aos "nossos melhores gramáticos", dizendo que eles "não têm escrúpulo de tomar essa palavra do grego". Como ele não menciona mais nada a respeito, fica pairando uma dúvida em relação ao fato de isso poder ser uma censura ou uma aprovação.

Ainda uma observação sobre definições de Bluteau: como foi citado acima, ele define gira como a "linguagem dos marotos". Mas o que é ser maroto no século XVIII? Vejamos o que se encontra no verbete, conforme consta no volume V (1716, p. 340):

MARÔTO. poderà derivar-fe do Hebraico Maroud, que val o melmo que Pedinte, que os que chamamos Marotos, faõ rapazes da ínfima plebe, mal compoltos, \& mal enfinados. Infimus puer, à imitação de Terencio, que chama à canalha, Infimi homines. Puer, explebeia Saete.

No volume IX, suplemento ao Vocabulario (1727, p. 20, posterior, portanto, à segunda impressão do livro de Argote), há o verbete MAROTAGE, ou Marotagem,

${ }^{19}$ Deveria ser: pronunciaõ ... 
antes de MAROTO (agora sem o acento circunflexo que aparecia no quinto volume). Vejamos o que mudou em uma década:

MAROTAGE, ou Marotagem. A fez do povo. Plebecula, ae, Fem. Populi faex, aecis. Fem. Infima multitudo, dinis, Fem. Cic.

Saiba toda a Fidalguia,

Sabia toda a marotage.

Oraç. Academ. De Fr. Simaõ, 219.

MAROTO. Dizem, que ElRey de Portugal, Dom Affonfo VI. fe fervia com hum moço Francez, chamado Marot, donde pallou o nome Maroto para os rapazes da plebe.

Fez, singular de fezes, significa no séc. XVIII "borra, aquilo que se deposita no fundo de uma emulsão; aquilo que sobra", correspondente talvez ao ralé, moderno. Porém, os dois versos de Fr. Simão, assim isolados, são ambíguos e não permitem decidir se fidalguia é igual à marotage...

Em maroto, a anedota, que daria conta de uma possível alternativa de etimologia para a palavra, é sobre D. Afonso VI, o rei deposto por não consumar o casamento com Maria Francisca de Sabóia, o que inviabilizaria gerar um herdeiro ao trono. Segundo Natário (2008, p. 238-247), depois do afastamento do rei, pelas Cortes, em janeiro de 1668, a rainha casou com o irmão dele, o regente D. Pedro, depois D. Pedro II, para quietação do reino (e, lógico, para Portugal não ter que devolver o valioso dote). Como Afonso VI levava vida libertina, parece que há alusão apimentada no sentido dado a "Dom Afonso VI se servia com um moço francês chamado Marot".

Assim, podemos vislumbrar quanta carga semântica negativa comportava a definição de gíria e de marotos, no século XVIII. Mas, ainda assim, para Contador de Argote a gíria constituía um dialeto do português e cumpria registrá-lo, ainda que com restrições de uso.

\section{CONCLUSÃo}

Quanto trabalho ainda há por fazer em matéria de datação de palavras para compor a história da língua portuguesa. Lembrar que estabelecer datas de aparição de palavras não é só inserção na linha do tempo: as palavras nos revelam fatos da vida social $^{20}$ e cultural dos povos, elas contam como os povos mudam, como foi a sua evolução. No nosso caso, refazer a trajetória de inclusão da palavra dialeto representa

${ }^{20}$ Veja-se que a inclusão da anedota sobre D. Afonso VI pode alargar a acepção da palavra maroto a partir da década de sessenta do século XVII. 
uma tomada de atitude diferente dos autores em relação à variação e à mudança da língua.

A par da noção de que as línguas mudam no tempo, fato já admitido pelos primeiros gramáticos, começam a surgir concepções sobre variedades da língua que coexistem no mesmo tempo, no mesmo espaço - o reino de Portugal -, ainda que sejam consideradas inadequadas, más, rústicas e que fenômenos considerados como modos diferentes de falar a língua nada mais sejam que usos antigos que ainda permanecem na boca dos falantes do interior. Ou, ainda, as primeiras impressões causadas pela introdução de palavras das línguas bárbaras (os empréstimos, diríamos hoje) nos dialetos ultramarinos, naquele português meio diferente, que também conservava palavras antigas, ou como lidar com inovação e preservação ao mesmo tempo.

Com referência a dialetos como variedades da língua portuguesa, vimos que Barreto ainda emprega a palavra só com sentido geral, em 1671. Bluteau, no Vocabulario, em 1713, já expõe a palavra como modo de falar a mesma língua nas diferentes partes do Reino, contrapondo o português das províncias da Beira, de Entre Douro e Minho àquele empregado "pelos filhos de Lisboa". Argote, em 1725, vai definir dialeto de maneira semelhante à de Bluteau, estendendo a denominação aos dialetos da Extremadura, do Algarve, aos rústicos, aos de profissão (poético e prosaico), à gíria e aos dialetos ultramarinos.

E, embora dialecto já conste do Diccionario da língua portugueza, na edição reformada e acrescentada por Moraes Silva (BLUTEAU, 1789), parece estranho que no dicionário Houaiss (HOUAISS; VILLAR, 2009, p. 679) a forma dialeto receba datação de 1942, pois é nessa entrada que são descritas todas as acepções da palavra dialeto. Algumas linhas acima, há o registro da forma dialecto: "1694. o m. q. dialeto". Ora, antes dessa data, a grafia dialeto já havia sido utilizada por Barreto em 1671 (p. 183, como assinalado em nossa Introdução, e como pode ser comprovado também na versão em pdf disponível na internet).

A concentração das acepções da palavra, no Houaiss, sob o verbete grafado dialeto enviesa o fato de alguns dos significados do termo terem sido usado antes dessa data (1942), mas com a grafia dialecto, como na obra de Amadeu Amaral, O Dialecto caipira, publicado em 1920. Mas, antes disso, já José de Alencar havia usado dialeto ${ }^{21}$ no romance regionalista Til, de 1872, ao que parece, na acepção de língua, mas com avaliação negativa:

Depois arrancou do peito cavernoso a mesma toada do acalanto, cujas palavras truncava por forma que somente se percebia delas a sonância confusa e estranha.

${ }^{21}$ Como consultei a versão de domínio público, talvez no original de Alencar estivesse grafado dialecto. 
Dir-se-ia que ela cantava em algum dialeto africano, tão bárbara era a pronúncia com que se exprimia (Zana, personagem do capítulo XVII; negrito nosso).

E, falando em dialeto caipira, Leone (2013, p. 97) assinala o fato de que a palavra caipira(s) aparece pela primeira vez no romance Til, de Alencar. Consultando o pdf do romance, verifiquei haver ali 22 ocorrências da palavra (mas nenhuma associada a dialeto).

Assim, o presente trabalho conclui com uma abertura a novas pesquisas, para se poder lançar mais luzes sobre os empregos das palavras e as datas a que podemos recuar na sua datação. E é sempre bom lembrar que as datas são válidas até que se encontre novo documento, mais antigo.

\section{REFERÊNCIAS}

ALENCAR, José de. Til. 2. ed. São Paulo: Melhoramentos. Disponível em: https://bit.ly/2zFPVDVtiljA. Acesso em: 23 ago. 2019.

AMARAL, A. O dialecto caipira. Gramática. Vocabulário. São Paulo: Casa Editora “O Livro", 1920.

ASSUNÇÃO, C. A arte da grammatica da língua portuguesa de António José Reis Lobato. Estudo, ed. crítica, manuscritos e textos subsidiários. Lisboa: Academia de Ciências, 2000.

BARRETO, J. F. Ortografia da lingua portugueza. Lisboa: Na Officina de Joam da Costa, 1671.

BLUTEAU, Raphael. Vocabulario portuguez e latino, aulico, anatomico ..., autorizado com exemplos dos melhores escritores portugueses, e latinos ... Coimbra: No Collegio das Artes da Cia. de Jesus, 1712-1728. 10v.

BLUTEAU, Raphael. Diccionario da lingua portugueza. Reformado e accrescentado por Antonio de Moraes Silva. Tomo I: A-K; Tomo II: L-Z. Lisboa: Na Off. De Simão Thaddeo Ferreira, 1789.

BRANDÃO, J. Grandeza e abastança de Lisboa em 1552. Lisboa: Livros Horizonte, 1990. (Organização e notas de José Felicidade Alves).

CAMÕES, J. (Ed.). Teatro português do século XVI. Teatro Profano. v. 1., t. I. Lisboa: IN-CM, 2007.

CONTADOR DE ARGOTE, D. J. Regras da lingua portugueza, espelho da latina. 2. ed. impr. Lixboa Occidental: Na Officina da Musica, 1725 [1721]. 
HOUAISS, A.; VILLAR, M. S. Dicionário Honaiss da língua portuguesa. 1. reimpr., com alterações Rio de Janeiro: Objetiva, 2009.

KEMMLER, R. O gramático Jerónimo Contador de Argote e as duas edições das Regras da Lingua Portugueza, espelho da Latina (1721-1725). In: MORENO, A. et al. (Org.). XXIX Encontro Nacional da Associação Portuguesa de Linguística. Textos selecionados. 2013. p. 289-300.

LEITE, M. Q. A construção da norma linguística na gramática do século XVIII. Alfa, Revista de Linguística, v. 55, n. 2, p. 665-684. 2011. Disponível em: https://bit.ly/3fUsbMUnorlin. Acesso em: 15 ago. 2019.

LEITE DE VASCONCELLOS, J. Estudos de filologia mirandesa. Vol. I. Lisboa: Imprensa Nacional, 1900. Disponível em: https://bit.ly/2Wy6hYmleivas. Acesso em: 13 ago. 2019.

LEITE DE VASCONCELLOS, J. Opusculos, IV: Filologia. Parte II. Coimbra: Imprensa da Universidade, 1929.

LEITE DE VASCONCELLOS, J. Esquisse d'une dialectologie portugaise. Thèse pour le Doctorat de l'Université de Paris. Faculté des Lettres. 2. ed. Lisboa: Centro de Estudos Filológicos, 1970 [1901]. (Com aditamentos e correções do autor, preparada, com base no exemplar conservado no Museu Etnológico "Dr. Leite de Vasconcellos", por Maria Adelaide Valle Cintra). Disponível em: https://bit.ly/2WZcP13esquisse. Acesso em: 05 ago. 2019 .

LEONE, J. B. Datação de fenômenos lexicais e expressões idiomáticas na obra de Juó Bananére: subsídios para o estudo diacrônico do português brasileiro. 2013. Tese (Doutorado em Filologia e Linguística) - Universidade de São Paulo, São Paulo, 2013.

MARQUES, R. do N. As duas edições da gramática de Contador de Argote (1721, 1725). Revista da ABRALIN, v. 16, n. 1, p. 205-222, 2017.

MENON, O. P. da S. Contador d'Argote: um dialetógo / sociolinguista avant la lettre? In: CONGRESSO INTERNACIONAL DE DIALETOLOGIA E SOCIOILINGUÍSTICA, 5., 2018, Salvador. (Apresentação oral).

NASCENTES, A. O linguajar carioca. 2. ed. Rio de Janeiro: Organização Simões, 1953 [1922].

NATÁRIO, A. Portuguesas com história. Séculos XVI e XVII. Lisboa: Temas \& Debates, 2008.

ROMANO, Valter P.; SEABRA, Rodrigo D. Menino, guri ou piá? Um estudo diatópico nas regiões Centro-Oeste, Sudeste e Sul a partir dos dados do Projeto Atlas Linguístico do Brasil. Alfa, Revista de Linguística, v. 58, n. 2, p. 463-497, jun./dez. 2014. Disponível em: https://bit.ly/3fSESIemenino. Acesso em: 26 ago. 2019. 